\title{
Estratégias para criar no trabalho: proposição teórica e validação psicométrica de medida ${ }^{1}$
}

\author{
Melissa Machado de Moraes $^{2}$ \\ Suzana Maria Valle Lima \\ Universidade de Brasília, Brasília-DF, Brasil
}

\begin{abstract}
Resumo: Há poucas pesquisas empíricas sobre criatividade no trabalho no Brasil, a despeito da relevância do tema. Este estudo teve como objetivo a proposição teórica e a validação psicométrica de medida de estratégias para criar no trabalho. Tal construto se refere aos esforços empreendidos pelo indivíduo para favorecer a criação de ideias novas e úteis na resolução de problemas de trabalho. A coleta de dados ocorreu em autarquia federal, via internet, obtendo-se uma amostra de 688 participantes. Foi realizada análise fatorial exploratória, e a solução hierárquica encontrada é composta de 44 itens formando cinco fatores de primeira ordem $(\alpha=0,75$ a 0,95$)$, um dos quais possui duas facetas e todos se agregam em único fator geral de ordem superior. Os resultados indicaram a adequação da medida proposta, que em muito pode contribuir para o avanço das pesquisas em criatividade no trabalho, e apontam caminhos para o refinamento da medida.
\end{abstract}

Palavras-chave: criatividade, psicologia organizacional, solução de problemas.

\section{Creative strategies at work: theoretical proposition and validation of psychometric measure}

\begin{abstract}
There is little empirical research about creativity at the workplace in Brazil, despite the topic's relevance. This study aimed to present a theoretical proposition and psychometric validation of a measure of creative strategies at work. Such construct refers to the efforts individuals exert so to favor the creation of new and useful ideas focused on work problem solving. Data were collected via Internet in a Brazilian governmental organization in a sample of 688 employees. Exploratory factor analysis was conducted and the found hierarchical factor solution for creative strategies is composed of 44 items distributed in five first-order factors $(\alpha=.75$ to .95$)$, one with two facets, and all of them are grouped into a single higherorder factor. Results indicate the proposed measure is adequate and can greatly contribute to the advancement of research on creativity at the workplace and indicate directions to refine the measure.
\end{abstract}

Keywords: creativity, industrial psychology, problem solving.

\section{Estrategias creativas en el trabajo: proposición teórica y validación psicométrica de medidas}

\begin{abstract}
Resumen: Hay pocas investigaciones empíricas brasileñas sobre creatividad en el trabajo, a pesar de la relevancia de este tema. Este estudio tuvo como objetivo la proposición teórica y la validación psicométrica de una medida de estrategias para crear en el trabajo. Tal concepto se refiere a los esfuerzos del individuo para favorecer la creación de ideas nuevas y útiles para la solución de problemas de trabajo. La recolección de datos ocurrió en una autarquía federal, vía Internet, obteniéndose 688 participantes. Fue realizado análisis factorial exploratorio y la solución jerárquica encontrada tiene 44 ítems formados en cinco factores de primer orden $(\alpha=0,75$ a 0,95$)$, uno con dos facetas y todos agregándose en un solo factor general de orden superior. Los resultados indican la adecuación de la medida propuesta, que puede contribuir en el avance de las investigaciones sobre creatividad en el trabajo, y apuntan caminos para el refinamiento de la medida.
\end{abstract}

Palabras clave: creatividad, psicología industrial, solución de problemas.

$\mathrm{Na}$ atualidade, quer pela necessidade de aprimorar sua capacidade adaptativa, ampliar sua prosperidade ou simplesmente garantir sua sobrevivência, as organizações engajam-se nos mais diversos esforços de mudança (Stoner \& Freeman,

1 Este trabalho deriva de parcela da dissertação de mestrado da primeira autora, realizada sob patrocínio do Programa de Pós-graduação do Banco Central do Brasil, com orientação da segunda autora, e defendida em novembro de 2006, no Instituto de Psicologia da Universidade de Brasília. Este texto foi revisado seguindo Acordo Ortográfico da Língua Portuguesa (1990), em vigor a partir de $1^{\circ}$ de janeiro de 2009.

2 Endereço para correspondência:

Melissa Machado de Moraes. Banco Central do Brasil. Departamento de Gestão de Pessoas, Coordenação de Planejamento e Pesquisa em Gestão de Pessoas. Setor Bancário Sul (SBS), Quadra 3, Bloco B Ed. Sede, 17o. andar. CEP 70.074-900. Brasília-DF, Brasil. E-mail: melissammoraes@gmail.com
1995), sendo este um tema recorrente de estudiosos do comportamento organizacional e gestores em geral. A sobrevivência organizacional é atribuída à capacidade de manter coerência interna e consistência com o ambiente externo, a despeito das turbulências (Silva, 2003), o que requer das organizações capacidade de inovar seus processos, produtos e serviços. Independentemente da vertente teórica, as ideias criativas são habitualmente apontadas como elemento necessário à inovação (Alencar, 1998; Bruno-Faria, 2003; Choi, 2004; Lima, 2003; Terra, 2000). Assim, o estudo da criatividade no contexto organizacional pode trazer à tona aspectos que subsidiariamente favoreçam a ocorrência da inovação e, por conseguinte, auxiliem as organizações a lidar melhor com os desafios impostos pela instabilidade vigente.

A relevância de temas de pesquisa que tratem desses desafios não é nova, tampouco a sua emergência. Rousseau (1997) 
aborda pesquisas que refletem a transformação de organizações "como entidades" para organizações "como processos", com maior capacidade adaptativa. A autora identifica essa transformação como sinal de uma nova era organizacional, que traz à baila diferentes aspectos como questões de pesquisa relevantes. É interessante observar, contudo, a incidência de pesquisas nacionais sobre alguns temas que Rousseau destaca como mais sensíveis a essas mudanças. Borges-Andrade, Coelho Jr. e Queiroga (2006) coordenaram uma revisão da produção nacional de pesquisas empíricas em comportamento organizacional publicadas no período de 1996 a 2004. Nesta revisão, que categoriza a produção em classes de assuntos, mudança organizacional é tema responsável por $14 \%$ dos trabalhos realizados. Associando a ele os tópicos aprendizagem e cultura, construtos correlatos por vezes confundidos com mudança (Lima, 2003), tem-se 32\% da produção nacional. Criatividade e resolução de problemas, entretanto, representam tão somente $2 \%$ das pesquisas realizadas no período, sendo alguns dos temas de comportamento organizacional menos estudados. Fica evidenciada, portanto, a necessidade de avançar nos estudos brasileiros sobre criatividade no ambiente de trabalho.

No intuito de encontrar o caminho para alavancar a tímida produção empírica nacional sobre o tema, vale observar a evolução histórica do estudo da criatividade, que vem obtendo espaço cada vez maior entre os tópicos investigados em Psicologia (Runco, 2004). É preciso verificar que diferentes aspectos da criatividade têm prevalência nessas investigações, a depender da época em questão. A ênfase inicial dos estudos em criatividade era o indivíduo criativo e a relação e a distinção entre criatividade, inteligência e personalidade, evidenciadas pelo conteúdo da primeira revisão sobre o tema publicada no Annual Review of Psychology, de Barron e Harrington (1981). Não obstante ainda sejam realizados estudos em criatividade sobre inteligência e personalidade, estes já não visam mais sua validação discriminante, ora consolidada (Vincent, Decker, \& Mumford, 2002).

A visão antropocêntrica da criatividade, embora permaneça dominante na idealização do fenômeno (Alencar, 1998), aos poucos vem cedendo espaço a outras abordagens. Runco (2004) comenta, por exemplo, o decréscimo de estudos envolvendo personalidade nas décadas de 1970 e 1980, acompanhado do aumento de pesquisas com foco social. A migração do foco no indivíduo para o foco no contexto também foi observada por Fleith (2002) a partir da década de 1990, embora sua análise refira-se à produção sobre criatividade na educação, área em que se concentra a maioria dos estudos do tema em nosso país. O aumento comentado por Runco, por sua vez, refere-se ao estudo da criatividade em contextos sociais diversos. Mais recentemente, como apontado por Alencar e Fleith (2003a), são verificadas na pesquisa internacional sobre criatividade abordagens que privilegiam o foco na interação entre aspectos individuais, sociais, culturais e históricos. No entanto, é destacado que essas contribuições mais recentes não têm sido contempladas nos estudos brasileiros.
Na presente iniciativa de contribuir para a investigação da criatividade nas organizações teve-se por base, portanto, a necessidade de aprofundamento das pesquisas que abordam a interação indivíduo-contexto apontada por diversos estudiosos de criatividade (Alencar \& Fleith, 2003a; Amabile, 1997; Runco, 2004). Isso porque tal abordagem parece melhor abarcar a complexidade do fenômeno em foco, favorecendo sua compreensão e estabelecendo os pilares para futuras intervenções. Estudos com essa abordagem contribuem, ainda, para o desenho customizado de soluções, visto que tendem a contemplar artefatos para lidar com as especificidades inerentes ao processo criativo em cada domínio ou contexto. Assim, seus resultados garantiriam aplicabilidade e favoreceriam a geração dos impactos almejados pelas organizações.

A investigação dos processos psicológicos subjacentes ao comportamento criativo, a partir dessa abordagem sistêmica, requer a consideração de antecedentes proximais e específicos que desempenhem função moderadora ou mediadora. Na busca desses possíveis antecedentes teve-se por base as proposições de Amabile (1997), que destaca os componentes individuais e contextuais que influem na criatividade e na inovação organizacionais. Da parte do indivíduo, Amabile aponta expertise, pensamento criativo e motivação intrínseca como elementos essenciais à criatividade, que será tanto maior quanto maior forem seus níveis - trata-se do que a autora chama de interseç̧ão da criatividade. No contexto, práticas de gestão, recursos e motivação organizacional para inovar são definidos como os elementos que impactam a criatividade e a inovação. $\mathrm{O}$ principal pressuposto em suas proposições é que os aspectos contextuais afetam a criatividade pela sua influência nos aspectos individuais, em especial na motivação para a tarefa. Alencar e Fleith (2003a), ao comentarem o modelo de Amabile, reiteram que o indivíduo deve se sentir mais motivado quando a atividade é desafiadora e lhe interessa, acarretando maior envolvimento.

$\mathrm{Na}$ literatura verifica-se que um construto motivacional em especial - autoeficácia para criar - tem se apresentado como variável mediadora dos efeitos de aspectos individuais e contextuais no desempenho criativo (Choi, 2004; Tierney $\&$ Farmer, 2004). No entanto, tendo em conta os desdobramentos esperados de autoeficácia, bem como sua conceituação em termos da crença do indivíduo em sua capacidade de organizar e executar cursos de ação necessários para a consecução de desempenhos almejados (Bandura, 1982; Pajares, 2004), é razoável supor que o desempenho criativo seja precedido da mobilização de recursos cognitivos, afetivos e comportamentais que contribuam para sua ocorrência. Nesta lacuna hipotetizada entre autoeficácia para criar e desempenho criativo no trabalho reside o espaço a ser ocupado pelo construto ora investigado.

Este estudo, portanto, tem como objetivo a proposição conceitual de estratégias para criar no trabalho, bem como o desenvolvimento e a validação de instrumento para sua mensuração. Na primeira parte deste artigo se oferecem elementos para melhor caracterizar o novo construto, explicando-o 
a partir do paralelo no qual sua concepção inicial foi inspirada - estratégias de aprendizagem. Na segunda parte são descritos o método de construção do instrumento e de coleta de dados, os resultados obtidos e sua discussão. Conclui-se analisando as contribuições e as limitações deste trabalho e propondo uma agenda de pesquisa para aprimoramento do conceito e da medida propostos.

\section{Estratégias para criar no trabalho: caracterização do construto}

A caracterização do construto estratégias para criar no trabalho foi realizada a partir do construto paralelo estratégias de aprendizagem. Nesta seção, parte-se da proximidade entre aprendizagem e criatividade, esclarecendo a pertinência da analogia utilizada. Em seguida, apresenta-se uma síntese da literatura sobre estratégias de aprendizagem no trabalho, em que é caracterizada a estrutura teórica e empírica do construto, tecendo-se algumas considerações adicionais sobre sua relevância. Por fim, é estabelecida a conceituação de estratégias para criar no trabalho e apontados seus elementos constituintes, bem como apresentadas suas propriedades presumidas, estabelecendo-se as bases iniciais para sua investigação.

\section{Aprender e criar: afinidade dos fenômenos}

Criatividade por vezes é entendida como qualidade das pessoas capazes de atos criativos; outras vezes como qualidade dos resultados desses atos; e, mais comumente, é vista como o processo que gera tais resultados. Embora haja razoável variação nos conceitos de criatividade, há concordância em termos de seus elementos constituintes habituais: utilidade e novidade são atributos frequentemente associados às ideias criativas (Alencar \& Fleith, 2003b; Bruno-Faria, 2003, 2004; Runco, 2004). O processo criativo, por sua vez, é compreendido como tendo início na identificação ou na percepção do problema e finalizando no refinamento da ideia ou da solução gerada, sem, no entanto, planejar sua implantação. Destaca-se que o entendimento adotado neste estudo é que o processo criativo nas organizações de trabalho sempre envolve a resolução de problemas, ainda que estes não estejam explicitados a princípio (Moraes, 2006).

Há várias definições para o termo aprendizagem na psicologia, mas de forma geral ele se refere às mudanças duradouras de comportamento do indivíduo decorrentes de sua interação com o contexto e não apenas fruto do processo natural de maturação (Abbad \& Borges-Andrade, 2004). Da mesma forma que há múltiplas definições de aprendizagem, também são diversos os tipos de aprendizagem. A maioria dos teóricos, porém, classifica resultados de aprendizagem em três domínios - cognitivo, afetivo e psicomotor -, sendo o cognitivo aquele que abarca desde evocação de informações, desenvolvimento de compreensão, até ampliação de capacidades intelectuais, inclusive as metacognitivas (Reigeluth \& Moore, 1999). Observado em mais detalhe o conteúdo de algumas taxonomias de aprendizagem, no tocante ao domínio cognitivo, evidenciam-se os pontos em que os fenômenos criar e aprender se assemelham, como exemplificado a seguir.

Abbad e Borges-Andrade (2004), ao apresentarem a taxonomia de Bloom e cols. (citados por Abbad \& BorgesAndrade, 2004), descrevem os objetivos de aprendizagem que a integram, entre os quais a síntese, em que se requer do aprendiz a produção de algo novo, dando-se especial importância à singularidade e à originalidade de sua ação. $\mathrm{Ou}$ seja, os resultados mais complexos nesta taxonomia parecem englobar a capacidade criativa do indivíduo. A hierarquia de resultados de aprendizagem proposta por Gagné (1985), por sua vez, prevê três grandes categorias para o domínio cognitivo: informação verbal, habilidades intelectuais e estratégias cognitivas. Nas habilidades intelectuais, o aprendiz constrói regras de ordem superior aplicáveis à resolução de problemas novos, retratando mais uma vez a afinidade entre resultados de aprendizagem mais complexos e criatividade, posto que o ineditismo do problema consta de várias definições do fenômeno (Mumford, 2000; Scott, Leritz, \& Mumford, 2004). $\mathrm{Na}$ categoria estratégias cognitivas "o aprendiz precisa ele mesmo definir o problema e depois encontrar uma maneira de solucioná-lo, não dispondo de regras para serem combinadas" (Abbad \& Borges-Andrade, 2004, p. 254), caracterização que muito se aproxima da definição de criatividade proativa de Kaufmann (2004). As afinidades dos fenômenos expostas redundaram no uso do construto paralelo estratégias de aprendizagem na concepção inicial do presente tópico de interesse - estratégias para criar no trabalho.

\section{Estratégias de aprendizagem: construto paralelo}

Estratégias de aprendizagem, em termos gerais, referem-se aos esforços nos quais os indivíduos se engajam para aprender. Podem ser intencionais, sendo selecionadas e controladas pelo aprendiz, ou seu uso pode ser automatizado, o que liberaria capacidade mental para outras atividades. É possível, ainda, que sejam de uso restrito a determinados domínios, ou que sejam válidas para uma ampla variedade de situações. No processo de aprendizagem, indivíduos lançam mão necessariamente de uma ou várias estratégias, visto que muitas vezes são imprescindíveis para que aprendam, mas é razoável supor que haja diferenças individuais quanto à natureza das estratégias utilizadas (Warr \& Allan, 1998).

Para os estudos no âmbito organizacional, Warr e Allan (1998) sugerem uma estrutura que agrega nove estratégias de aprendizagem no trabalho em três categorias, considerando ainda dois tipos distintos de estratégias: primárias e de autorregulação. As estratégias primárias são aquelas usadas quando do engajamento direto com o conteúdo sendo aprendido; já as estratégias de suporte, que impactariam indiretamente o aprendizado, são compostas de procedimentos de autorregulação. A descrição dessa estrutura consta na Tabela 1. Vale destacar que os autores enfocaram estratégias de aprendizagem no treinamento profissional de adultos, buscando aquelas que fossem genéricas o suficiente para serem úteis em diferentes cenários de trabalho, restringindo-se, todavia, àquelas cujas evidências empíricas à época apontavam como mais significativas. 
Tabela 1

Estratégias de aprendizagem no trabalho: estrutura teórica e definições

\begin{tabular}{|c|c|c|c|}
\hline \multicolumn{3}{|c|}{ Estratégias de Aprendizagem } & Definições \\
\hline \multirow{6}{*}{ 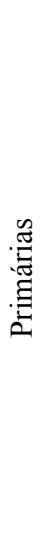 } & \multirow{4}{*}{ Cognitivas } & Reprodução & $\begin{array}{l}\text { Repetição para si mesmo do material que está sendo aprendido. Não envolve reflexão } \\
\text { sobre o significado do material, nem sua alteração, tampouco a visão de como ele } \\
\text { poderia estar relacionado a outro material. }\end{array}$ \\
\hline & & Organização & $\begin{array}{l}\text { Identificação de aspectos centrais e criação de esquemas mentais que agrupam e } \\
\text { relacionam tais aspectos, de tal sorte a impor nova organização ao conteúdo. }\end{array}$ \\
\hline & & Elaboração & $\begin{array}{l}\text { Estabelecimento de conexões entre o material a ser aprendido e o conhecimento } \\
\text { preexistente. Exame de implicações, buscando mudar a forma como o material é visto } \\
\text { perante as demais informações. }\end{array}$ \\
\hline & & Aplicação Prática & $\begin{array}{l}\text { Aplicação prática dos próprios conhecimentos enquanto aprende, ou tentativa de fazê- } \\
\text { lo, com o objetivo de melhorar a compreensão do material a ser aprendido. }\end{array}$ \\
\hline & \multirow{2}{*}{ Comportamentais } & $\begin{array}{l}\text { Busca de Ajuda em } \\
\text { Material Escrito }\end{array}$ & $\begin{array}{l}\text { Pesquisa e localização de informações em documentos, manuais, internet e outras } \\
\text { fontes não sociais, no intuito de favorecer a compreensão do material a ser aprendido }\end{array}$ \\
\hline & & $\begin{array}{l}\text { Busca de Ajuda } \\
\text { Interpessoal }\end{array}$ & $\begin{array}{l}\text { Busca de auxílio de outras pessoas, como pares e professores, para favorecer o } \\
\text { entendimento do material a ser aprendido. Vai além do recebimento rotineiro de } \\
\text { instrução. }\end{array}$ \\
\hline \multirow{3}{*}{$\begin{array}{l}\stackrel{0}{0} \\
\stackrel{0}{Z} \\
\text { ڤ }\end{array}$} & \multirow{3}{*}{ Autorregulação } & Controle Emocional & $\begin{array}{l}\text { Afastamento da ansiedade e prevençãa de desatenção decorrente da intromissão de } \\
\text { demais pensamentos ligados à ansiedade. }\end{array}$ \\
\hline & & Controle Motivacional & $\begin{array}{l}\text { Manutenção da motivação e atenção, a despeito de haver pouco interesse pela tarefa } \\
\text { em questão. }\end{array}$ \\
\hline & & $\begin{array}{l}\text { Monitoramento da } \\
\text { Compreensão }\end{array}$ & $\begin{array}{l}\text { Avaliação do grau em que os objetivos de aprendizagem estão sendo atendidos, para } \\
\text { promover eventuais modificações de comportamento necessárias. }\end{array}$ \\
\hline
\end{tabular}

Adaptado de Warr e Allan (1998).

Os resultados de análises fatoriais dão suporte à estrutura apresentada por Warr e Allan (1998), embora com pequenas diferenças na agregação das estratégias cognitivas de organização e elaboração, conforme os estudos conduzidos por Warr e Downing (2000) e por Holman, Epitropaki e Fernie (2001). Nas investigações brasileiras de construção e validação de medidas de estratégias de aprendizagem em diferentes contextos (Lopes-Ribeiro, 2005; Pantoja, 2004; Zerbini, 2003) os resultados de análises fatoriais também se aproximam da estrutura apresentada por Warr e Allan. Todavia, há importante reorganização de fatores, incluindo a mescla de aspectos cognitivos e comportamentais.

Da mesma forma que no presente trabalho a ideia de estratégias de aprendizagem foi usada como inspiração para o desenvolvimento de construto análogo, Pilati e BorgesAndrade (2005) percorreram caminho similar na proposição conceitual e na construção de medida de estratégias para aplicação no trabalho do aprendido em treinamento. Foi verificado um fator de cunho comportamental e outro composto de cognições e afetos, dando continuidade a um padrão de fatores mesclados observado nos resultados brasileiros. Cabe destacar, todavia, que a operacionalização dos aspectos afetivos realizada por esses autores privilegia afetos relativos à aplicação do aprendido, distanciando-se da autorregulação constante da proposição original de Warr e Allan (1998).

A despeito da necessidade de esclarecimentos adicionais sobre a estrutura teórica e empírica de estratégias de aprendizagem, a relevância deste construto para os estudos em Psicologia Organizacional é corroborada por diversos aspectos. As evidências empíricas sugerem relação entre aprendizagem e uso de estratégias para aprender no trabalho, entre treinamento em estratégias e sucesso na aprendizagem, além de sua interação com variáveis individuais na explicação de resultados de aprendizagem (Pantoja, 2004; Warr \& Allan, 1998; Warr \& Downing, 2000).

\section{Estratégias para criar no trabalho: um novo construto}

Estratégias para criar no trabalho são esforços empreendidos pelo indivíduo que favoreçam a criação de ideias novas e úteis para a resolução de problemas de trabalho. Podem ser processos mentais nos quais os indivíduos se engajam; comportamentos demonstrados; ou ainda ações de autorregulação com vistas a facilitar o processo de resolução criativa de problemas no trabalho. As estratégias para criar no trabalho são, portanto, ações que facilitam a identificação e a compreensão de problemas no trabalho; a preparação para resolução destes problemas; o surgimento da ideia ou solução procurada; e, por fim, a verificação da validade e da utilidade da ideia proposta e seu aprimoramento. A definição proposta de estratégias para criar no trabalho abarca aspectos cognitivos, comportamentais e de autorregulação, tal qual estratégias de aprendizagem, assim como a noção de engajamento consciente. Refere-se, ainda, aos esforços que visem favorecer o processo criativo no trabalho (Moraes, 2006). Da mesma forma que ocorre com estratégias de aprendizagem, é razoável supor semelhança do construto com estilos cognitivos, especialmente se consideradas medidas de estilos criativos e estilos de resolução criativa de problemas.

O foco do construto aqui proposto não são ferramentas ou técnicas ensinadas em eventos instrucionais ou aprendidas em material didático sobre resolução criativa de problemas e semelhantes, embora o indivíduo também possa lançar 
mão destes para favorecer a resolução criativa de problemas. O critério diferencial que merece atenção é a suposição de que estratégias para criar no trabalho, embora possam ser ensinadas formalmente, em geral decorreriam da experiência do indivíduo, de suas habilidades cognitivas prévias, de sua aprendizagem natural e de demais aspectos porventura envolvidos na sua busca pela resolução do problema de trabalho em foco. Acredita-se que tais estratégias seriam maleáveis, variando conforme o contexto de aplicação e o domínio envolvido, pressupostos que se alinham tanto com os atributos de estratégias de aprendizagem já explanados (Pantoja, 2004; Warr \& Allan, 1998) quanto com as peculiaridades do processo criativo (Runco, 2004). Atenderiam, também, ao quesito de variável com potencial explicativo para interação indivíduo - contexto, além de possível preditora do desempenho criativo no trabalho.

A definição da estrutura subjacente ao construto estratégias para criar no trabalho derivou da adequação das estratégias de aprendizagem às especificidades do processo criativo, a partir da revisão de literatura sobre ambos os temas, preservando a composição tripartite de cognições, comportamentos e autorregulação. A despeito do uso de estratégias de aprendizagem no trabalho como construto análogo, não se supõe que a estrutura teórica do construto sugerido seja semelhante ou distinta do que a inspirou. $\mathrm{O}$ entendimento adotado é que não há elementos suficientes na literatura em criatividade sobre o tema investigado, da maneira aqui proposta, para supor estrutura própria. Da mesma forma, as medidas brasileiras de estratégias de aprendizagem no trabalho e afins apontam para diferentes composições, não provendo embasamento para supor tal estrutura. A partir dessas reflexões se deu a construção da medida de estratégias para criar no trabalho, detalhada adiante.

Na seção a seguir são explicitados o método utilizado na realização da presente pesquisa, os resultados encontrados e sua discussão. Primeiramente se caracterizam a amostra, o instrumento e os procedimentos usados neste estudo. São então apresentados os resultados obtidos na extração e na rotação de fatores, na aferição de sua consistência interna e homogeneidade e, ainda, na exploração de facetas e fatores de segunda ordem. Por fim, são discutidos os resultados encontrados tendo em conta os objetivos estabelecidos e a literatura da área.

\section{Método}

\section{Participantes}

Os dados foram coletados em uma organização pública do poder executivo sediada em Brasília com projeções regionais nas nove principais capitais brasileiras. Tal organização contava em seu quadro à época da coleta com 4.597 servidores e 1.593 terceirizados, estagiários e menores aprendizes. Registrou-se a participação de 1.055 indivíduos, dos quais 878 completaram a pesquisa. A exclusão de dados omissos e extremos resultou em banco de dados contendo
688 observações. A quase totalidade dessa amostra é composta de servidores (95\%) homens (76\%), que cursaram Pósgraduação (57\%), com mais de 50 anos (49\%) e 20 anos de empresa $(47 \%)$. A prevalência é de respondentes com formação nas áreas de Ciências Sociais Aplicadas e Ciências Exatas, especialmente em Administração e Contabilidade (26,89\%), Economia (19,04\%) e Engenharia (13,37\%); sendo que a maioria (62\%) atua em sua área de formação, ainda que parcialmente.

Vale destacar que as características da amostra são compatíveis com as da população, pois se trata de organização em que há maioria masculina (81\%) e na qual o nível superior é requisito para ingresso em $89 \%$ dos postos de trabalho. Há programa de incentivo à Pós-graduação e gratificações por qualificação formal, o que explica a prevalência de respondentes pós-graduados. Ademais, também coerente com as características da população, observa-se na amostra concentração de respondentes de mais idade e tempo de empresa.

\section{Instrumento}

A medida de estratégias para criar no trabalho foi construída em três etapas. A etapa inicial foi composta de revisão de literatura da área e inspeção de medidas afins existentes (Pantoja, 2004; Warr \& Downing, 2000), de forma a subsidiar a operacionalização do construto pretendida. Foram formulados 92 itens, submetidos a seguir à validação de conteúdo por peritos, para verificar a pertinência teórica e a clareza destes.

A validação ocorreu em conjunto com outras medidas em construção pelas pesquisadoras, que tratavam de autoeficácia para criar, orientação motivacional para o trabalho e contexto sociopsicológico para inovação. O processo de validação de conteúdo foi realizado por cinco peritos - quatro doutores em psicologia e um doutorando, todos com experiência em criatividade e aprendizagem. Os peritos receberam formulário contendo as definições dos construtos e tabela de dupla entrada composta de todos os itens e nomes dos construtos, para que assinalassem a que construto o item se refere. Adicionalmente, foi solicitado que avaliassem a clareza dos itens, utilizando uma escala de quatro pontos (1-sem nenhuma clareza; 4-totalmente claro).

Foram mantidos intactos itens que obtiveram ao menos $80 \%$ de concordância no tocante ao construto a que se referem e no mínimo média de 3,4 no quesito clareza. Itens que não atendiam a esses critérios, mas cuja manutenção se fazia necessária para representar a totalidade do construto investigado, foram ajustados com o auxílio de duas mestrandas em psicologia experientes na construção de instrumentos. Desta etapa de corte e ajustes resultaram 66 itens de estratégias para criar no trabalho.

A terceira etapa consistiu na validação semântica dos itens para garantir que eram compreensíveis para o públicoalvo, da qual participaram três servidores, com diferentes funções e níveis de escolaridade. Após demais ajustes, a versão final do instrumento continha 63 itens de estratégias 
para criar no trabalho, a serem respondidos em uma escala de frequência composta de dez pontos, ancorada nas extremidades (1-nunca; 10-sempre), além de onze itens sociodemográficos.

\section{Procedimento}

Para a coleta de dados foi negociada com a área de recursos humanos da organização a remessa de mensagem eletrônica a todos os servidores, terceirizados, estagiários e menores aprendizes através das listas de distribuição oficiais. Nessa mensagem constava o convite para participar da pesquisa, o link para o formulário eletrônico do instrumento e informações sucintas sobre o teor da pesquisa e a afiliação das pesquisadoras, bem como esclarecimentos quanto à não obrigatoriedade de participação e garantia de sigilo das respostas individuais. Na sequência, procederam-se análises fatoriais exploratórias do conjunto de variáveis, cujos resultados são expostos em mais detalhe a seguir.

\section{Resultados}

As análises exploratórias de dados apontaram para uma pequena incidência de abandono do preenchimento da pesquisa, que acarretou a exclusão de 25 casos em que mais de $10 \%$ das questões foram deixadas em branco. $\mathrm{Na}$ inspeção dos itens de estratégias para criar no trabalho foi pequena a presença de dados omissos, havendo menos de $1,3 \%$ por variável. Optou-se pela eliminação seletiva dos dados via tratamento pairwise. Foi realizada inspeção visual prévia das curvas de distribuição das variáveis contínuas, bem como apreciados seus índices de assimetria e curtose, sendo percebida leve assimetria negativa (até -1,25), mas insuficiente para prejudicar as análises pretendidas. A investigação de casos extremos apontou 58 possíveis casos extremos univariados com $\mathrm{z}<3,29(p<0,001)$ e 107 casos extremos multivariados ( $p \leq 0,001$ da distribuição $X^{2}$ na distância de Mahalanobis), que foram excluídos.

A base de dados usada para as análises fatoriais, portanto, possui 688 observações, garantindo a proporção de 10,92 sujeitos por item. Embora esse porte seja considerado adequado por alguns autores (Pasquali, 2004; Tabachnick \& Fidell, 2001), há que se considerar o teor essencialmente exploratório dos procedimentos ora adotados, bem como sua sujeição a erros, aspectos enfatizados por Costello e Osborne (2005). A verificação de linearidade entre pares de variáveis foi realizada pela inspeção visual de scatterplots de pares com índices de assimetria mais discrepantes, não tendo sido observado nenhum indício de relações curvilíneas. Foi constatada, ainda, a inexistência de singularidade e multicolinearidade das variáveis através da inspeção da matriz de correlações e da matriz anti-imagem. A fatorabilidade da matriz de correlações foi examinada a partir do tamanho e da prevalência das correlações e do valor de seu determinante, que neste caso se aproxima de zero (det=3,67 E-15). O índice de adequação da amostra de Kaiser-Meyer-Olkein $(\mathrm{KMO}=0,961)$ obtido também evidencia a viabilidade da análise fatorial.

A questão subsequente à decisão de usar a análise fatorial, vista a fatorabilidade da matriz acima exposta, é definir a quantidade de fatores que devem ser extraídos, considerada uma decisão crucial por Zwick e Velicer (1986). A técnica de análise paralela, sugerida por esses autores como o método mais preciso, foi adotada nesta pesquisa e indicou a extração de seis fatores. O passo seguinte consistiu na extração desses fatores, usando o método dos eixos principais (Principal Axis Factoring - PAF) e a rotação oblíqua (direct oblimin), pois a suposição de que os fatores são correlacionados contraindica o uso de rotação ortogonal (Reise, Waller, \& Comrey, 2000). A exploração inicial da matriz pattern, contendo o conjunto de itens e suas respectivas cargas nos fatores, permitiu verificar que há itens que não contribuíam para uma solução fatorial satisfatória. Dos 63 itens iniciais foram preservados 46 , sendo doze itens cortados por serem fracos (carga menor que 0,32 ) ou complexos (cargas maiores que $0,32 \mathrm{em}$ mais de um fator); e cinco itens por não aderirem teoricamente ao fator alocado ou cuja saída aprimora a fidedignidade do fator medida pelo alfa de Cronbach $(\alpha)$. Preservaram-se para interpretação, dessa maneira, as variáveis com cargas superiores a 0,32 , conforme regra prática apontada por Tabachnick e Fidell (2001).

Após a retirada de itens deste porte é recomendável a realização de nova análise fatorial, seguindo processo habitual na construção de medidas (Clark \& Watson, 1995; Costello \& Osborne, 2005; Tabachnick \& Fidell, 2001). Embora persistisse a indicação de extração de seis fatores pela análise paralela, optou-se pela extração de cinco, visto que a análise fatorial exploratória inicial produziu um fator com apenas dois itens. A matriz pattern resultante da análise fatorial exploratória final não apresenta itens que incorram nas condições de exclusão utilizadas na rodada inicial. Acreditase, portanto, que compõe uma solução fatorial satisfatória e parcimoniosa, a ser relatada a seguir com suas especificidades, bem como avaliadas a consistência interna e a homogeneidade dos fatores nela contidos.

\section{Consistência interna e homogeneidade dos fatores}

A solução fatorial final contém 44 itens distribuídos em cinco fatores que explicam $50,02 \%$ da variância observada antes da rotação e cujos alfas de Cronbach oscilam entre 0,75 e 0,95 . A média da correlação entre itens verificada nos fatores, por sua vez, oscila entre 0,266 e 0,513 e sua variância entre 0,006 e 0,009, valores satisfatórios considerando a recomendação de Clark e Watson (1995) de que tal média recaia na faixa de 0,15 a 0,50 e possua variância limitada. A estrutura empírica dos cinco fatores de primeira ordem está representada na Tabela 2, com a descrição dos itens que a compõem e suas respectivas cargas fatoriais e comunalidades. 
Moraes, M. M., \& Lima, S. M. V. (2009). Estratégias para criar no trabalho.

Tabela 2

Distribuição dos itens por fator, cargas fatoriais e comunalidades (h2)

\begin{tabular}{|c|c|c|}
\hline Itens & Carga & $\mathbf{h}^{2}$ \\
\hline \multicolumn{3}{|l|}{ Fator 1 Pensamento Flexível (19 itens, $\alpha=0,95)$} \\
\hline \multicolumn{3}{|l|}{ Média correlação entre itens 0,481 (variância 0,006 ) } \\
\hline Para resolver um problema de trabalho procuro combinar diferentes ideias. & 0,77 & 0,67 \\
\hline Busco entender um problema de trabalho de vários ângulos diferentes. & 0,74 & 0,67 \\
\hline Combino diferentes perspectivas na geração de ideias sobre meu trabalho. & 0,69 & 0,69 \\
\hline Reflito sobre qual a melhor maneira de implementar uma ideia de trabalho. & 0,67 & 0,53 \\
\hline $\begin{array}{l}\text { Quando tenho uma ideia no trabalho, eu tento descobrir quais seriam suas consequências para as demais atividades do } \\
\text { meu setor. }\end{array}$ & 0,64 & 0,54 \\
\hline Mesmo quando domino um assunto de trabalho, me esforço para enxergá-lo de uma nova forma. & 0,64 & 0,52 \\
\hline Ao analisar um problema de trabalho, penso em como poderia redefini-lo. & 0,61 & 0,47 \\
\hline Junto ideias diferentes para obter a solução de um problema de trabalho. & 0,60 & 0,68 \\
\hline Penso em várias formas de realizar uma tarefa no trabalho. & 0,59 & 0,60 \\
\hline Quando reflito sobre soluções para um problema, penso em como afetariam as demais áreas de meu trabalho. & 0,59 & 0,53 \\
\hline Uso muitas abordagens ao refletir sobre um assunto de trabalho. & 0,58 & 0,63 \\
\hline Refino as ideias que tenho no trabalho, melhorando as soluções propostas. & 0,58 & 0,63 \\
\hline Para entender um problema de trabalho, tento associar informações de diversas origens. & 0,56 & 0,58 \\
\hline Tento reformular um problema de trabalho para compreendê-lo melhor. & 0,54 & 0,55 \\
\hline Avalio a utilidade das soluções que encontro para um problema de trabalho. & 0,53 & 0,61 \\
\hline Busco gerar muitas alternativas de solução para um problema. & 0,53 & 0,50 \\
\hline Para opinar sobre um assunto no meu trabalho, recolho variadas informações sobre ele. & 0,51 & 0,47 \\
\hline $\begin{array}{l}\text { Considero as mais diversas ideias para o trabalho que me vierem à cabeça, mesmo que possam parecer inadequadas a } \\
\text { princípio. }\end{array}$ & 0,48 & 0,49 \\
\hline Listo mentalmente as possíveis soluções para um problema de trabalho. & 0,43 & 0,37 \\
\hline
\end{tabular}

Fator 2 Imaginação e Introspecção ( 8 itens, $\alpha=0,75$ )

Média correlação entre itens 0,266 (variância 0,006 )

Para quebrar a rotina, faço minhas tarefas de forma pouco habitual.

Brinco mentalmente com ideias bizarras e inusitadas sobre o meu trabalho.

Busco um ambiente isolado para poder focar só no problema de trabalho que estiver analisando.

Para ter ideias diferentes no trabalho, faço de conta que não conheço nada sobre um tema.

Imagino a solução perfeita para um problema de trabalho, mesmo que seja fantasiosa.

Quando tento resolver uma questão de trabalho eu a contemplo por períodos prolongados.

Ao refletir sobre soluções para um problema de trabalho, deixo para criticá-las depois.

Converso mentalmente comigo mesmo, me incentivando a ser criativo no trabalho.

Fator 3 Controle Emocional (5 itens, $\alpha=0,76$ )

Média correlação entre itens 0,389 (variância 0,009)

Quando não consigo resolver um problema de trabalho, me distraio temporariamente com outros assuntos.

Quando não consigo chegar a uma solução para um problema de trabalho, "dou um tempo".

Quando a ansiedade me atrapalha em ter ideias no trabalho, procuro relaxar pensando em coisas boas.

No trabalho, intercalo momentos de intensa atividade na resolução de problemas com momentos de descontração e relaxamento.

Quando me sinto pressionado para ter ideias no trabalho, busco formas de reduzir a pressão.

$0,53 \quad 0,37$

$0,49 \quad 0,46$

$0,45 \quad 0,25$

$0,44 \quad 0,39$

$0,43 \quad 0,40$

$0,42 \quad 0,37$

$0,38 \quad 0,19$

$0,32 \quad 0,35$

Fator 4 Leitura Inspiradora (4 itens, $\alpha=0,81$ )

Média correlação entre itens 0,513 (variância 0,008 )

Para ter ideias no trabalho, mantenho-me atualizado lendo artigos e textos da minha área de atuação.

Leio sobre assuntos diversos para que surjam novas ideias sobre meu trabalho.

Busco material de leitura sobre o problema de trabalho que tiver que resolver.

Seleciono as melhores fontes de material sobre minhas atividades, para poder acessá-las em caso de problemas no trabalho.

Fator 5 Interação e Analogia ( 8 itens, $\alpha=0,84$ )

Média correlação entre itens 0,394 (variância 0,007 )

Quando tenho um problema de trabalho para resolver, eu procuro ajuda de colegas mais experientes.

Para melhor compreender situações novas no trabalho, procuro por aspectos que me são familiares.

Eu discuto o problema que estiver resolvendo com meus colegas de trabalho.

Verifico se os métodos que já conheço se aplicam na resolução de novos problemas de trabalho.

Eu converso sobre um problema de trabalho com pessoas de interesses semelhantes aos meus.

Reconheço limitações nas minhas próprias ideias sobre meu trabalho.

Para entender melhor minhas tarefas, eu as comparo com experiências prévias de trabalho.

$0,70 \quad 0,47$

$0,67 \quad 0,43$

$0,59 \quad 0,50$

$0,57 \quad 0,35$

$0,43 \quad 0,39$

Ao analisar uma questão de trabalho, se necessário, mudo minha opinião inicial. 
Analisando o conteúdo dos itens do primeiro fator são encontradas estratégias cognitivas afetas a associação de perspectivas, diversificação de ideias, reformulação de problemas e avaliação extrínseca pertinentes à geração de ideias e à resolução de problemas no trabalho. $\mathrm{O}$ aparente elemento subjacente a tais itens é a flexibilidade de pensamento, que permite vislumbrar uma mesma questão de variadas maneiras. Dessa forma, esse fator foi denominado Pensamento Flexível (19 itens, $\alpha=0,95)$.

No segundo fator são encontradas estratégias cognitivas relativas à exploração de alternativas inusitadas, incluindo fantasia e suspensão de julgamento, na busca da resolução de problemas e da geração de ideias no trabalho. Há também estratégias de autorregulação que contribuem para a manutenção de foco, esforço e motivação envolvidos nessa exploração. Esse fator foi denominado Imaginação e Introspecção ( 8 itens, $\alpha=0,85$ ), pois estes parecem ser os elementos agregadores que caracterizam a maioria de seus itens.

$\mathrm{O}$ terceiro fator possui itens que explicitam estratégias de autorregulação relativas ao controle emocional, visando minimizar ou precaver-se contra a ansiedade e a frustração inerentes à resolução de problemas e à geração de ideias no trabalho. Foi denominado, portanto, Controle Emocional (5 itens, $\alpha=0,76$ ). O fator quatro, por sua vez, foi denominado Leitura Inspiradora ( 4 itens, $\alpha=0,81$ ), pois todos os seus itens refletem estratégias comportamentais relacionadas à leitura ou à busca de material de leitura com o intuito de favorecer a resolução de problemas e a geração de ideias no trabalho.

Os itens do quinto fator retratam estratégias comportamentais relativas à busca de ajuda interpessoal para a resolução de problemas no trabalho, incluindo itens que retratam maleabilidade que favoreceria tal interação. Também possui estratégias cognitivas ligadas ao uso de analogias na resolução de problemas de trabalho e no favorecimento de sua compreensão. Esse fator foi denominado Interação e Analogia (8 itens, $\alpha=0,84$ ).

\section{Exploração de facetas nos fatores e de fatores de ordem superior}

Em alguns dos fatores extraídos foi possível identificar subconjuntos de itens que tratam de dimensões teóricas afins, porém distintas. Foi cogitada a existência de facetas nesses fatores, e para explorar essa possibilidade foram realizados os mesmos passos anteriores, incluindo análise de componentes principais, para aferir a fatorabilidade do conjunto de itens, a extração pelo método dos eixos principais (Principal Axis Factoring - PAF) e a rotação oblíqua (direct oblimin). Neste procedimento foram identificadas duas facetas para o fator Pensamento Flexível.

A primeira faceta é composta de 14 itens, com cargas fatoriais que oscilam de 0,37 a 0,92 e média de 0,67 . A consistência interna dessa faceta $(\alpha=0,94)$ indica elevada fidedignidade. A média das correlações entre itens é $0,518 \mathrm{com}$ variância de 0,006. Essa faceta é composta de itens que tratam de associação de perspectivas, diversificação de ideias e reformulação de problemas, sendo por isso denominada Integração e Variedade. Da segunda faceta constam cinco itens, cujas cargas fatoriais variam entre 0,49 e 0,78 e possuem carga fatorial média de 0,62 . Sua consistência interna $(\alpha=0,82)$ sugere fidedignidade satisfatória. A média de correlações entre itens é 0,473 e a variância, 0,005 . Essa faceta foi denominada Soluções e Efeitos, pois seus itens abordam ponderações sobre elementos externos às ideias e às soluções cogitadas, como suas consequências, opções de implantação e formas de opinar a esse respeito.

Adicionalmente, julgou-se oportuno explorar a existência de fator de segunda ordem, tendo em vista a correlação média entre fatores de primeira ordem $(r=0,31)$ e a prevalência de correlações moderadas $(r=0,12$ a 0,52$)$. Para este propósito foram utilizados os fatores de primeira ordem como variáveis de estudo (Floyd \& Widaman, 1995), e repetidos os procedimentos necessários para a definição do número de fatores a extrair. Houve convergência entre os critérios usados - K1, Cattell e análise paralela -, visto que todos apontaram para a extração de fator único. Mais uma vez, procedeu-se a análise fatorial através do método dos eixos principais (Principal Axis Factoring - PAF), impondo a extração de um fator.

$\mathrm{O}$ fator geral extraído foi denominado Estratégias para Criar no Trabalho. A correlação média entre itens é 0,458 com variância de 0,015 . O alfa de Cronbach $(\alpha=0,79)$ obtido para o fator indica fidedignidade moderada. Esse fator explica $57,20 \%$ da variância total observada e tem autovalor igual a 2,86. As cargas fatoriais apresentadas oscilam entre 0,52 (Controle Emocional) e 0,93 (Pensamento Flexível), compondo uma média de 0,68 .

A adoção de inúmeros passos para explorar uma solução hierárquica que representasse adequadamente o fenômeno investigado teve por base as ponderações de Floyd e Widaman (1995, p. 293) de que "soluções hierárquicas provavelmente são adequadas para muitos instrumentos psicológicos, pois a maioria dos construtos psicológicos é constituída de facetas múltiplas correlacionadas". Smith e McCarthy (1995) também consideram a identificação de fatores de ordem superior e de facetas imprescindível na construção e no refinamento de medidas, e comentam que se trata de procedimento subutilizado.

\section{Discussão}

Os resultados apresentados da validação estatística da medida de estratégias para criar no trabalho evidenciam claramente que se trata de solução fatorial robusta. Além da fidedignidade satisfatória de seus fatores, essa medida possui apenas dois itens com cargas fatoriais abaixo de 0,40 - outro indicativo da qualidade da solução identificada. A avaliação dessa medida, entretanto, não deve se restringir a esses aspectos. Um importante referencial no desenvolvimento do instrumento ora validado foi o construto paralelo estratégias de aprendizagem, de maneira que cabe comparar os resultados encontrados com a estrutura teórica a ele subjacente. 
A análise do conteúdo de cada fator de primeira ordem permite verificar a presença de estratégias cognitivas, comportamentais e de autorregulação, consubstanciando a pertinência da analogia adotada.

No tocante às estratégias cognitivas, a maioria se concentrou em um único fator, Pensamento Flexível, composto exclusivamente por elas, enquanto as demais se associaram às estratégias comportamentais e de autorregulação nos fatores Interação e Analogia e Imaginação e Introspecção, respectivamente. Elementos como associação, fluência, analogia, flexibilidade e sensibilidade para problemas constam da solução fatorial final. Entretanto, destacaram-se, por um lado, aqueles elementos relativos à associação e à flexibilidade, representados por fator robusto, e, por outro, sensibilidade a problemas, pela sua dispersão.

As estratégias comportamentais, ao contrário das cognitivas, demonstraram bastante coesão. Leitura Inspiradora agrega a totalidade de itens de busca de ajuda material presentes na solução fatorial adotada, da mesma forma que ocorre com Interação e Analogia, embora neste último tenha havido maior perda de itens originais, além de compor fator híbrido. Já no caso das estratégias de autorregulação, apenas aquelas referentes ao controle emocional estão adequadamente representadas e, embora alguns itens voltados para foco e motivação tenham se agregado ao fator Imaginação e Introspecção, vários itens construídos para esse fim não se sustentaram na solução fatorial final.

Observar os atributos da medida validada a partir da ótica do processo criativo, por sua vez, gera outras ponderações interessantes. A identificação das etapas mais beneficiadas pelas estratégias contidas em cada fator possibilitou verificar a prevalência das etapas de preparação, incubação e iluminação; enquanto identificação do problema e verificação foram menos contempladas. Ainda que este exercício de comparação seja limitado a priori, dadas as restrições da concepção de processo criativo linear e sistemático (Bruno-Faria, 2004), entende-se seu uso como um primeiro passo válido na compreensão dos resultados deste estudo.

Explorações adicionais são oportunas no caso dos elementos cuja presença na solução fatorial final é tímida, como os aspectos de sensibilidade a problemas (refinamento e reformulação) e referentes à autorregulação do foco e da motivação. Vale destacar, todavia, que a ausência de determinadas facetas ou fatores no construto latente ora investigado não pode ser interpretada como indicativo de sua inexistência empírica sem a consideração de explicações alternativas. Como sugerem Clark e Watson (1995), cabe refletir se os itens foram adequadamente redigidos, se a amostra é representativa em pontos relevantes para o construto em análise e se há suficiência de itens na representação do construto e de seus elementos constituintes. Por fim, também cabe avaliar a pertinência da proposição teórica subjacente. Ou seja, as mesmas preocupações presentes na construção inicial do instrumento devem ser retomadas nos esforços de refinamento.

No presente estudo, as pesquisadoras balizaram suas decisões pelo intento de produzir solução fatorial robusta e parcimoniosa, não se abstendo de promover as exclusões de itens necessárias para este fim. De fato, o resultado apresentado e ora discutido indica que se atingiu tal objetivo, visto que no estudo realizado a medida de estratégias para criar no trabalho demonstra qualidades psicométricas e adequação teórica satisfatórias. Não obstante, as sugestões de melhoria e recomendações para seu aprimoramento aqui expostas são imprescindíveis, tendo em conta a complexidade da empreitada pretendida, e devem ser consideradas nos esforços futuros de refinamento da medida.

\section{Considerações finais}

Os resultados encontrados apontam não apenas para a existência do construto estratégias para criar no trabalho, mas também para a pertinência da medida desenvolvida e do caminho usado na formulação de ambos: lançando mão de conhecimentos já consolidados na área de aprendizagem. Espera-se que a medida ora validada contribua para a construção de desenhos de pesquisa mais complexos, que contemplem a interação indivíduo-contexto e aprofundem o conhecimento disponível a seu respeito, quiçá oferecendo elementos para melhor ajustamento do indivíduo ao trabalho e aproveitamento de seu potencial criativo. Espera-se, portanto, que este trabalho seja precursor de estudos dessa natureza. Por fim, vale comentar sua aplicabilidade nas organizações de trabalho, visto que pode constituir importante ferramenta de diagnóstico, fornecendo subsídios para gestores atuarem no favorecimento do potencial criativo de seus colaboradores.

Há que se considerar, todavia, que o presente estudo teceu proposições tão somente a partir da revisão de literatura sem, no entanto, proceder ao levantamento de indicadores com representantes da população-alvo. Outra limitação devese ao fato de a coleta de dados ter ocorrido em apenas uma organização. É razoável supor, portanto, que outras nuanças do construto investigado não tenham sido evidenciadas em virtude da relativa homogeneidade da amostra. Dessa forma, sugere-se o refinamento da medida ora proposta, aprofundando as dimensões já identificadas e explorando novas dimensões. Sugere-se, ainda, sua aplicação em amostras diversificadas, garantindo a heterogeneidade necessária para a verificação da estabilidade da estrutura fatorial encontrada. Deve-se, oportunamente, proceder sua validação discriminante utilizando construtos fronteiriços, como estilo criativo, e evidenciar sua validade preditiva de desempenho criativo no trabalho.

Ademais, a partir da medida ora proposta é possível explorar a variação no uso de estratégias para criar no trabalho e sua eficácia em termos de diferentes tipos de processo criativo (por exemplo, reativo ou proativo), de problema (por exemplo, delimitado ou aberto), de clima para criatividade (por exemplo, estímulos e barreiras prevalentes), entre outras variáveis de domínio e contexto. Da mesma forma, pode-se investigar a variação no uso de estratégias para criar no trabalho e sua eficácia em termos de diferentes características 
individuais (por exemplo, estilos cognitivos, traços de personalidade, orientação motivacional, dentre outros). Por fim, é recomendável averiguar a interação entre variáveis individuais, contextuais e de domínio em delineamentos complexos que envolvam estratégias para criar no trabalho. São diversas as oportunidades de pesquisa decorrentes da aplicação e do refinamento da medida, sendo este estudo tão somente o primeiro passo nessa construção teórica. Ainda assim, os resultados preliminares (Moraes, 2006) apontam tal caminho como promissor. Conclui-se este artigo, portanto, reiterando a relevância do construto estratégias para criar no trabalho, que em muito pode contribuir para os avanços dos estudos brasileiros sobre criatividade nas organizações de trabalho.

\section{Referências}

Abbad, G., \& Borges-Andrade, J. E. (2004). Aprendizagem humana em organizações e trabalho. In J. C. Zanelli, J. E. Borges-Andrade, \& A. V. B. Bastos (Orgs.), Psicologia, organizações e trabalho no Brasil (pp. 237-275). Porto Alegre: Artmed.

Alencar, E. M. L. S. (1998). Promovendo um ambiente favorável à criatividade nas organizações. Revista de Administração de Empresas, 38, 18-25.

Alencar E. M. L. S., \& Fleith, D. S. (2003a). Contribuições teóricas recentes ao estudo da criatividade. Psicologia: Teoria e Pesquisa, 19, 1-8.

Alencar, E. M. L. S., \& Fleith, D. S. (2003b). Criatividade: Múltiplas perspectivas. Brasília, DF: EdUnB.

Amabile, T. M. (1997). Motivating creativity in organizations: On doing what you love and loving what you do. California Management Review, 40, 39-58.

Bandura, A. (1982). Self-efficacy mechanism in human agency. American Psychologist, 37, 122-147.

Barron, F., \& Harrington, D. (1981). Creativity, intelligence, and personality. Annual Review of Psychology, 32, 439476.

Borges-Andrade, J. E., Coelho Jr., F. A., \& Queiroga, F. (2006). Pesquisa sobre micro comportamento organizacional no Brasil: O estado da arte. Trabalho apresentado no II Congresso Brasileiro de Psicologia Organizacional e do Trabalho, Brasília, DF.

Bruno-Faria, M. de F. (2003). Criatividade, inovação e mudança organizacional. In S. M. V. Lima (Org.), Mudança organizacional: Teoria e gestão (pp. 111-141). Rio de Janeiro: EdFGV.

Bruno-Faria, M. de F. (2004). O processo criativo em individuos e grupos participantes de projetos inovadores. Tese de doutorado não publicada, Universidade de Brasília, Brasília, DF.

Choi, J. N. (2004). Individual and contextual predictors of creative performance: The mediating role of psychological processes. Creativity Research Journal, 16, 187-199.

Clark, L.A., \& Watson, D. (1995). Constructing validity: Basic issues in objective scale development. Psychological Assessment, 7, 309-319.
Costello, A. B., \& Osborne, J. W. (2005). Best practices in exploratory factor analysis: Four recommendations for getting the most from your analysis. Practical Assessment Research \& Evaluation, 10(7). Recuperado em 24 junho 2006, de http://pareonline.net/getvn.asp?v=10\&n=7

Fleith, D. S. (2002). Creativity in the Brazilian culture. In W. J. Lonner, D. L. Dinnel, S. A. Hayes, \& D. N. Sattler (Eds.), Online readings in psychology and culture. Washington: Center for Cross-Cultural Research, Western Washington University. Recuperado em 24 junho 2006, de http:// www.wwu.edu/ culture

Floyd, F. J., \& Widaman, K. F. (1995). Factor analysis in the development and refinement of clinical assessment instruments. Psychological Assessment, 16, 187-199.

Gagné, R. M. (1985). The conditions of learning and theory of instruction (4th ed.). New York: Holt, Rinehart \& Winston.

Holman, D., Epitropaki, O., \& Fernie, S. (2001). Understanding learning strategies in the workplace: A factor analytic investigation. Journal of Occupational and Organizational Psychology, 74, 675-681.

Kaufmann, G. (2004). Two kinds of creativity - but which ones? Creativity and Innovation Management, 13, 154165.

Lima, S. M. V. (2003). Estudo longitudinal das relações entre gestão e inovaçãotecnológica. Manuscrito não-publicado, Empresa Brasileira de Pesquisa Agropecuária.

Lopes-Ribeiro, R. (2005). Motivação para aprendizagem informal no trabalho: Construção de medidas $e$ investigação de modelo teórico. Dissertação de mestrado não-publicada, Universidade de Brasília, Brasília, DF.

Moraes, M. M. de (2006). Auto-eficácia e estratégias para criar no trabalho: Construção de medidas. Dissertação de mestrado não-publicada, Universidade de Brasília, Brasília, DF.

Mumford, M. D. (2000). Managing creative people: Strategies and tactics for innovation. Human Resource Management Review, 10, 313-351.

Pajares, F. (2004). Overview of social cognitive theory and of self-efficacy. Recuperado em 12 junho 2004, de http:// www.emory.edu/EDUCATION/mfp/eff.html

Pantoja, M. J. (2004). Estratégias de aprendizagem no trabalho e percepções de suporte à aprendizagem: Uma análise multinível. Tese de doutorado não publicada, Universidade de Brasília. Brasília, DF.

Pasquali, L. (2004). Análise fatorial para pesquisadores. Petrópolis, RJ: Vozes.

Pilati, R., \& Borges-Andrade, J. E. (2005). Estratégias para aplicação no trabalho do aprendido em treinamento: Proposição conceitual e desenvolvimento de uma medida. Psicologia Reflexão e Crítica, 18, 207-214.

Reigeluth, C. M., \& Moore, J. (1999). Cognitive education and the cognitive domain. In C. H. Reigeluth (Ed.), Instructional-design theories and models: Vol. 2. A new paradigm of instructional theory (pp. 51-68). Mahwah, NJ: Lawrence Erlbaum. 
Reise, S. P., Waller, N. G., \& Comrey, A. L. (2000). Factor analysis and scale revision. Psychological Assessment, 12, 287-297.

Rousseau, D. M. (1997). Organizational behavior in the new organizational era. Annual Review of Psychology, 48, 515-546.

Runco, A. (2004). Creativity. Annual Review of Psychology, 55, 657-687.

Scott, G., Leritz, L. E., \& Mumford, L. D. (2004). The effectiveness of creativity training: A quantitative review. Creativity Research Journal, 16, 361-388.

Silva, J. S. (2003). A mudança de época e o contexto global cambiante: Implicações para a mudança institucional em organizações de desenvolvimento. In S. M. V. Lima (Org.), Mudança organizacional: Teoria e gestão (pp. 65-110). Rio de Janeiro: EdFGV.

Smith, G. T., \& McCarthy, D. M. (1995). Methodological considerations in the refinement of clinical assessment instruments. Psychological Assessment, 7, 300-308.

Stoner, J. A. F., \& Freeman, R. E. (1995). Administração. Rio de Janeiro: Prentice-Hall do Brasil.

Tabachnick, B. G., \& Fidell, L. S. (2001). Using multivariate statistics. Boston, MA: Allyn and Bacon.

Terra, J. C. C. (2000). Gestão de criatividade. Revista de Administração, 35, 38-47.

Tierney, P., \& Farmer, S. M. (2004). Creative self-efficacy: Its potential antecedents and relationship to creative performance. Academy of Management Journal Briarcliff, 45, 1137-1148.

Vincent, A. S., Decker, B. P., \& Mumford, M. D. (2002). Divergent thinking, intelligence and expertise: A test of alternative models. Creativity Research Journal, 14, 163178.

Warr, P., \& Allan, C. (1998). Learning strategies and occupational training. In C. L. Cooper, \& I. T. Robertson (Eds.), International review of industrial and organizational psychology (pp. 84-121). London: John Wiley \& Sons.

Warr, P., \& Downing, J. (2000). Learning strategies, learning anxiety and knowledge acquisition. British Journal of Psychology, 91, 331-333.

Zerbini, T. (2003). Estratégias de aprendizagem, reações aos procedimentos de um curso via Internet, reações ao tutor e impacto do treinamento no trabalho. Dissertação de mestrado não-publicada, Universidade de Brasília, Brasília, DF.

Zwick, R., \& Velicer, W. (1986). Comparison of five rules for determining the number of components to retain. Psychological Bulletin, 99, 432-442.
Melissa Machado de Moraes é Mestre em Psicologia pelo Programa de Pós-graduação do Instituto de Psicologia da Universidade de Brasília, atualmente é Coordenadora de Planejamento e Pesquisa em Gestão de Pessoas do Banco Central do Brasil.

Suzana Maria Valle Lima é Professora Associada da Universidade de Brasília.
Recebido: $18 / 05 / 2008$

$1^{a}$ revisão: 20/03/2009

$2^{a}$ revisão: 19/06/2009

Aceite final: 02/07/2009 